\title{
Nonlinearities in the Economic Growth Rates of Taiwan and Hong Kong: A Bayesian Threshold
} Autoregression Approach

\author{
Wan-Shin $\mathrm{Mo}^{1}$, Masha Rahnamamoghadam ${ }^{2, *}$, Peter Summers ${ }^{3}$ \& Victor Valcarcel $^{2}$ \\ ${ }^{1}$ Dept. of Finance, Chung Yuan Christian University, Chung Li, 32023, Taiwan \\ ${ }^{2}$ Dept. of Economics, Texas Tech University, Lubbock, Texas 794009, United States \\ ${ }^{3}$ Phillips School of Business, High Point University, High Point, North Carolina 27262, \\ United States \\ *Corresponding author: Dept. of Economics, Texas Tech University, Lubbock, Texas 794009, \\ United States. Tel: 1-806-742-2466 x238. E-mail: m.rahnamamoghadam@ttu.edu
}

Received: February 19, 2014 Accepted: May 1, 2014 Published: June 25, 2014

doi:10.5296/rae.v6i2.5149ＵRL: http://dx.doi.org/10.5296/rae.v6i2.5149

\begin{abstract}
We analyze the extent to which low frequency movements in the economic activity of Taiwan and Hong Kong can be explained by those of their largest trading partners. We estimate posterior marginal probabilities across 312 different specifications for each country and computes Bayes' Factors as a model selection mechanism. Data suggests that a best fitting model requires a different specification for Hong Kong and Taiwan. Results show that economic growth rates in both Hong Kong and Taiwan are well described by a threshold model but with different types of nonlinear effects. Hong Kong's economic growth has a nonlinear effect on its expected future growth, but is unaffected by growth in the US, Japan or Taiwan. In contrast, we find a significant nonlinear spillover effect from Japan to Taiwan.
\end{abstract}

JEL Classification: F17, C22, E32

Keywords: economic growth, knowledge spillovers, nonlinear effects, threshold autoregressions 


\section{Introduction}

This paper investigates the extent to which the economic growth of some Southeast Asian countries can be explained by the economic growth of their more important trading partners. There is a vast literature on the relationship between trade and economic growth. For example, Levine and Renelt (1992) find a robust correlation between the ratio of international trade to GDP and economic growth and they posit that this relationship takes place through the investment channel. Borensztein et al (1998) and Frankle and Romer (1999) go as far as to imply causation from international trade to economic activity and they maintain that foreign direct investment (FDI) is an important determinant of a country's economic growth. Dollar and Kray (2003) find that FDI contributes to economic growth through institutions while Alvaro et al (2004) maintain that the contribution comes through the financial channel. Not everyone agrees, however. Rodriguez and Rodrick (2001) and Baldwin (2004) find that the relationship between trade policy (the former) or trade openness (the latter) and economic growth is weak at best.

A number of factors may be brought to bear on the debate. One is the perennial endogeneity issue-which one takes place first? Does trade lead to economic growth or does economic growth lead to trade? A common answer to this issue is to first assume a directionality (say trade leads to growth) and then find an instrument to prevent reverse causality.(Note 1) A second concern involves accounting for the different mechanisms through which trade might generate economic growth in a country. Thus it becomes important to allocate the extent to which do the benefits from trade come directly from its contribution to the current account or more indirectly though spillover effects on labor productivity or technological diffusion.(Note 2) Yet another channel for the relationship between trade and economic growth may ensue from trade liberalization as a catalyst for economic competition. For example Trefler (2004) shows that trade liberalization in Canada led to substantial increases in average productivity. An important concern, however, is whether the relationship between growth rates among trading partners is inherently nonlinear. If important nonlinearities in the economic growth rates among trading partners arise, then the standard cross-country regression methods motivated by the linearization of the technology process among those countries would be inadequate. This final concern informs our approach in this paper. Thus, we abstract from ascribing mechanisms that require the linearization of micro-founded first principle models. To our knowledge, the majority of the literature on this question relies on structurally imposing linear restrictions in the laws of motion that drive the dynamics of the relationships in question to motivate regression estimations. We depart from this standard approach by assuming that trade does contribute to economic growth to, subsequently, find statistical evidence of whether nonlinearities arise in the economic growth rates of major trading partners. Thus in this paper we investigate whether economic growth of Hong Kong and Taiwan can be explained by the economic growth of their more important trading partners and whether such spillovers are linear or not.

Taiwan has a significant trading relationship with the United States, Japan, and Hong Kong. 
Table 1. Taiwanese Foreign Trade

\begin{tabular}{|c|c|c|c|c|c|c|c|c|c|}
\hline \multicolumn{10}{|c|}{ Imports } \\
\hline \multirow{2}{*}{$\begin{array}{l}\text { Time } \\
\text { period }\end{array}$} & \multirow[t]{2}{*}{ Total $^{\mathrm{a}}$} & \multicolumn{2}{|c|}{ Japan } & \multicolumn{2}{|c|}{ USA } & \multicolumn{2}{|c|}{ Hong Kong } & \multicolumn{2}{|c|}{ China $^{c}$} \\
\hline & & Total $^{\mathrm{a}}$ & Share $^{\mathrm{b}}$ & Total & Share & Total & Share & Total & Share \\
\hline $1973-1979$ & 8,374.34 & 2,696.37 & $32 \%$ & $1,970.54$ & $24 \%$ & 135.87 & $02 \%$ & 0 & $0 \%$ \\
\hline 1980-1989 & $28,327.19$ & $8,259.10$ & $29 \%$ & $6,652.71$ & $23 \%$ & 711.50 & $03 \%$ & 0 & $0 \%$ \\
\hline 1990-1999 & $88,876.43$ & $24,907.25$ & $28 \%$ & $18,090.21$ & $20 \%$ & 1,827.93 & $02 \%$ & 2,513.36 & $3 \%$ \\
\hline 2000-2006 & $149,146.84$ & $37,241.99$ & $25 \%$ & 20.649 .11 & $14 \%$ & $2,078.20$ & $01 \%$ & $13,255.41$ & $9 \%$ \\
\hline \multicolumn{10}{|c|}{ Exports } \\
\hline 1973-1979 & 8,821.34 & $1,199.40$ & $14 \%$ & $3,267.71$ & $37 \%$ & 606.31 & $7 \%$ & 0 & $0 \%$ \\
\hline 1980-1989 & $28,327.19$ & $4,554.14$ & $12 \%$ & $15,485.92$ & $42 \%$ & $3,095.73$ & $8 \%$ & 0 & $0 \%$ \\
\hline 1990-1999 & $88,876.43$ & $10,560.67$ & $11 \%$ & $25,968.70$ & $26 \%$ & $20,992.71$ & $21 \%$ & 661.55 & $01 \%$ \\
\hline 2000-2006 & $149,164.84$ & $14,275.53$ & $09 \%$ & $29,695.50$ & $18 \%$ & $32,799.33$ & $20 \%$ & $24,929.47$ & $15 \%$ \\
\hline \multicolumn{10}{|c|}{ Source: Department of Statistics, Ministry of Finance, "Preliminary Statistics of Export and Import.” } \\
\hline \multicolumn{10}{|l|}{ Notes: } \\
\hline \multicolumn{10}{|c|}{ a Average for period, millions of dollars. } \\
\hline \multicolumn{10}{|c|}{ b Average for period as a share of total. } \\
\hline${ }^{\mathrm{c}}$ The data on & wan's imports $\mathrm{f}$ & om China begir & in 1991. & & & & & & \\
\hline
\end{tabular}

Panel A - Import Trade Values with Trading Partners

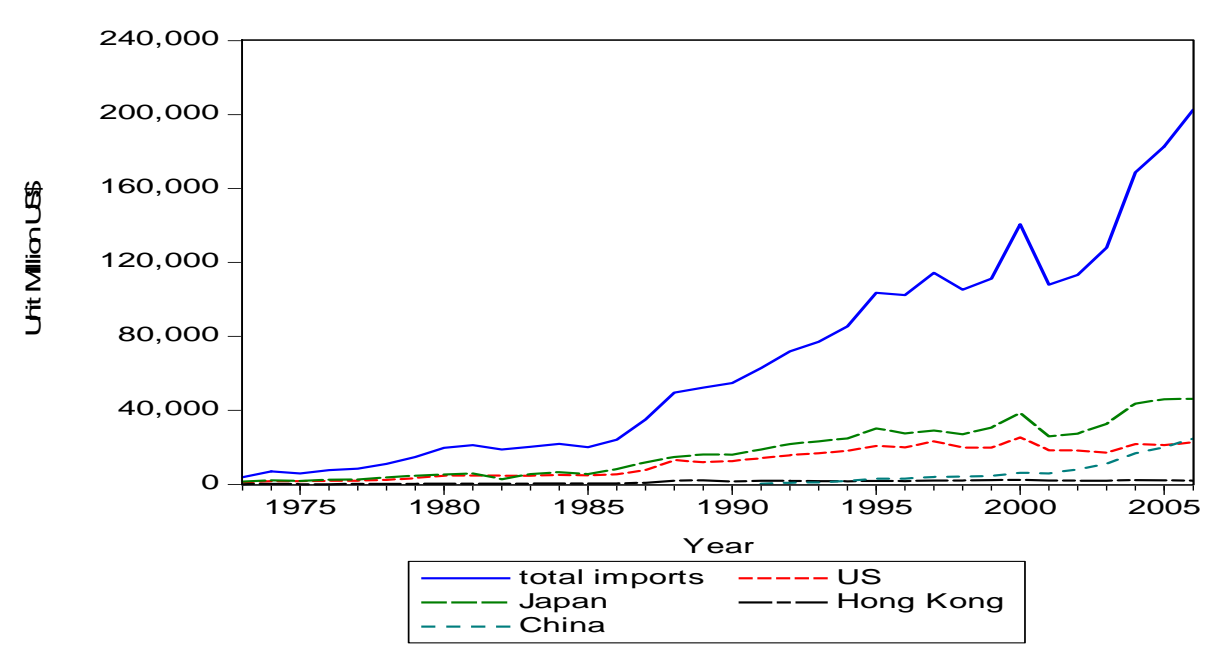


Panel B- Export Trade Values with Trading Partners

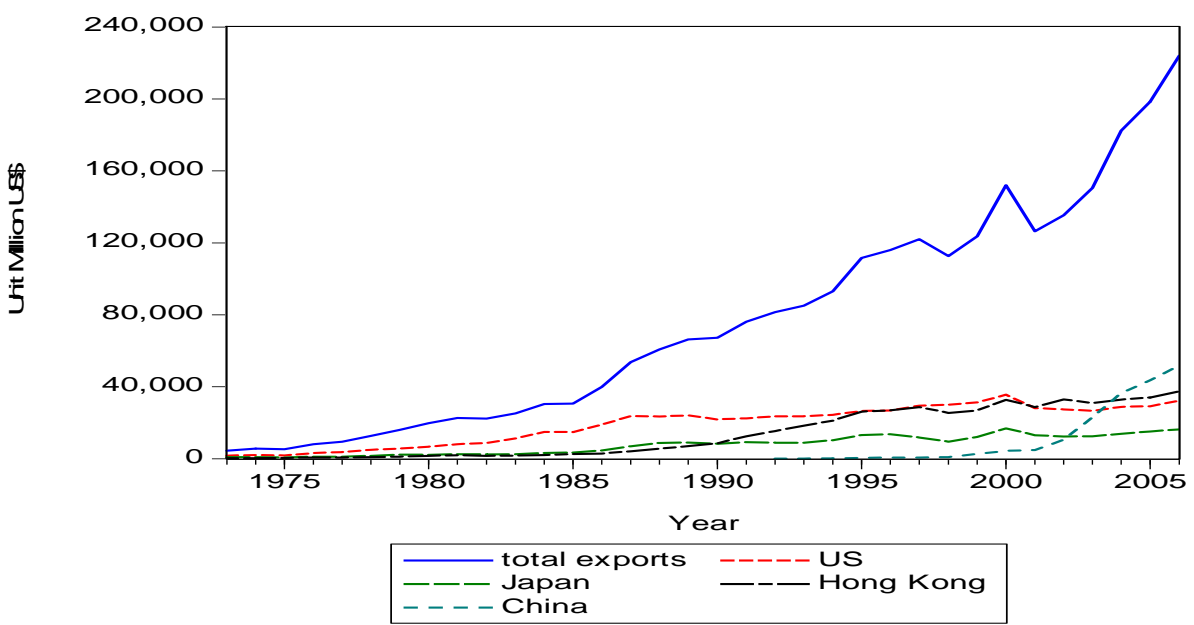

Panel C — Trade with the United States

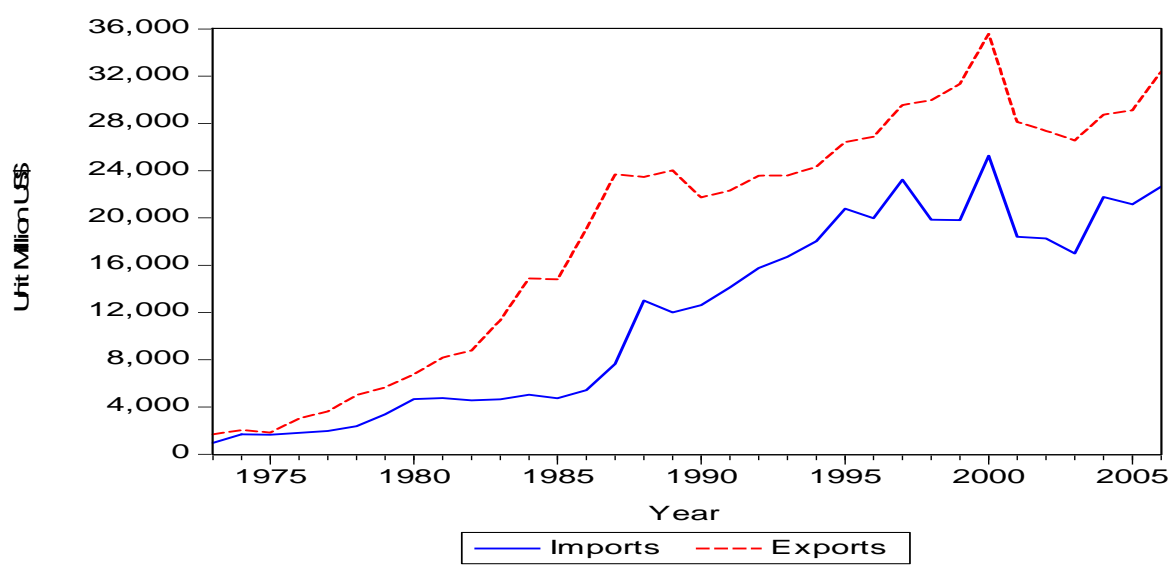

Panel D— Trade with Japan

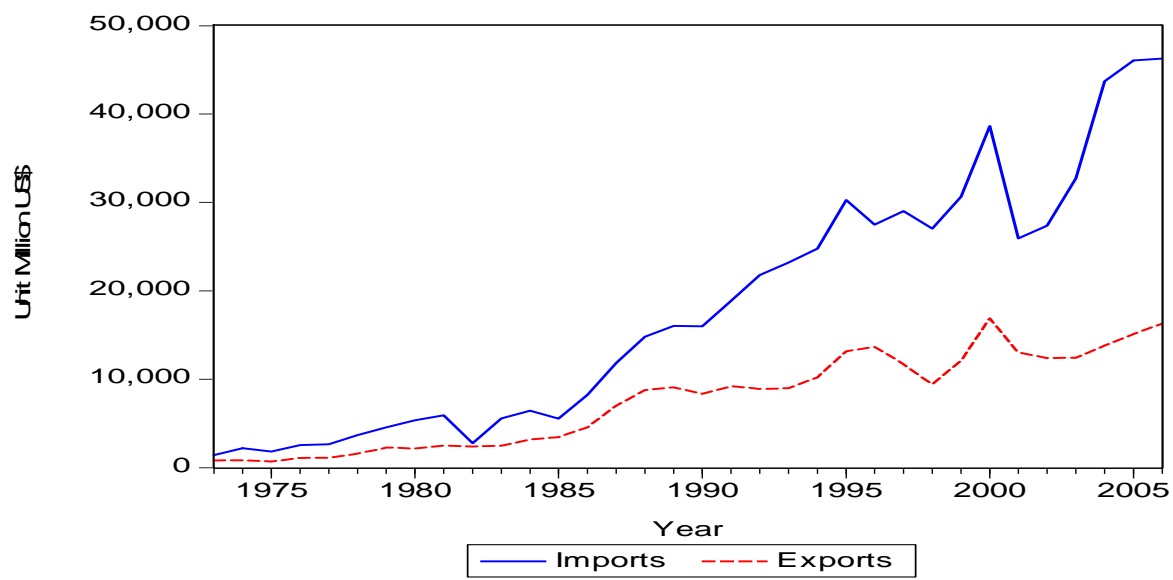


Panel E— Trade with Hong Kong

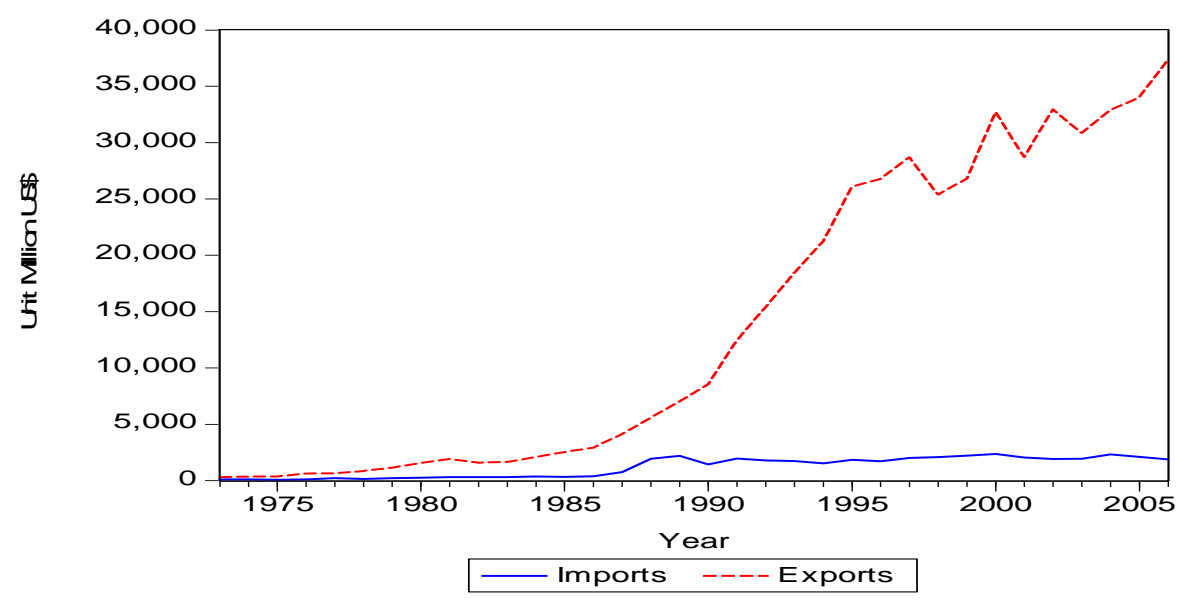

Panel F- Trade with China

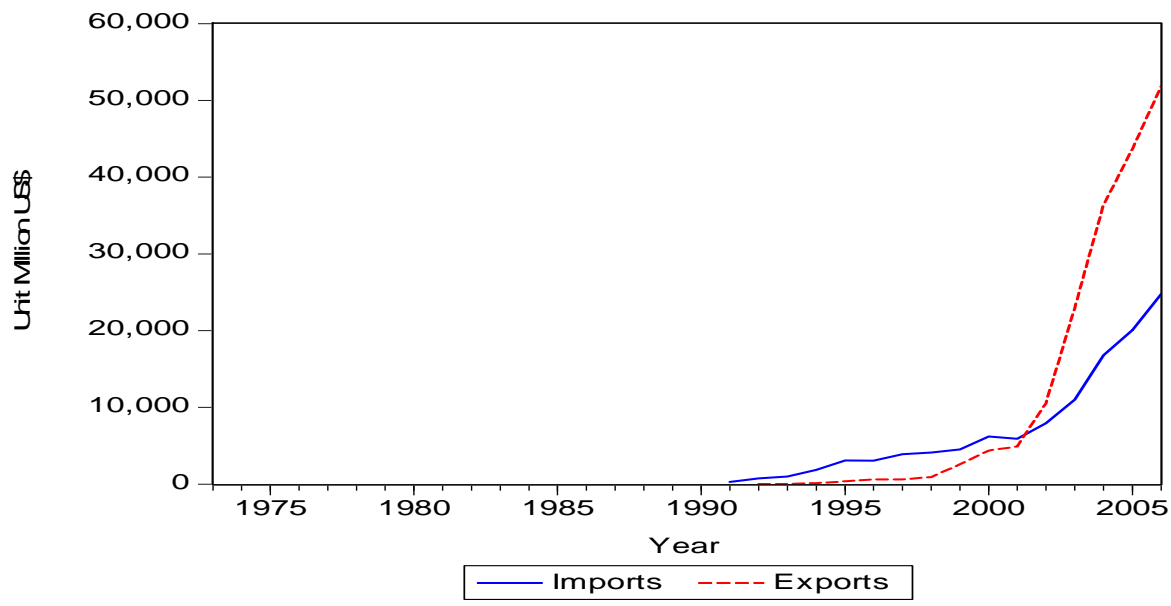

Figure 1. Taiwan’s Trade with Trading Partners

According to Table 1 and Figure 1, the United States was the biggest trade partner with Taiwan in the 1980s. ( Note 3) Taiwan exported many industrial products such as mechanical appliances and accessories, electronics, electrical appliances, personal computers and peripherals, metal products and transport equipment, furniture, and clothing to the U.S. In Particular 40\% of Taiwan's exports were destined to go to the U.S. Until 1999, Japan was the second largest trading partner of Taiwan next to the U.S. After Hong Kong's annexation to China in 1997, however, Taiwan started to increasingly sell goods to China through Hong Kong. Since then Hong Kong replaced Japan and has been a major exporter to Taiwan. After 2000, exports to Hong Kong took 20\% of Taiwan's total exports, while $9 \%$ of the exports went to Japan.

Before being returned to mainland China, Hong Kong's economy relied mainly on international trade due to its minimum trade restrictions and market mechanism. 
Table 2. Hong Kong Foreign Trade

\begin{tabular}{|c|c|c|c|c|c|c|c|c|c|}
\hline \multicolumn{10}{|c|}{ Imports } \\
\hline \multirow{2}{*}{$\begin{array}{l}\text { Time } \\
\text { period }\end{array}$} & \multirow[t]{2}{*}{ Total $^{\mathrm{a}}$} & \multicolumn{2}{|c|}{ Japan } & \multicolumn{2}{|c|}{ USA } & \multicolumn{2}{|c|}{ Taiwan } & \multicolumn{2}{|c|}{ China } \\
\hline & & Total $^{\mathrm{a}}$ & Share $^{\text {b }}$ & Total & Share & Total & Share & Total & Share \\
\hline $1973-1979$ & $9,884.39$ & $2,187.90$ & $22 \%$ & $1,216.96$ & $12 \%$ & 645.07 & $7 \%$ & $1,753.46$ & $18 \%$ \\
\hline 1980-1989 & $37,311.56$ & $7,555.83$ & $20 \%$ & $3,469.50$ & $9 \%$ & 3,146.89 & $9 \%$ & $10,638.56$ & $29 \%$ \\
\hline 1990-1999 & $157,046.44$ & $22,772.39$ & $15 \%$ & $11,834.24$ & $8 \%$ & $12,943.00$ & $9 \%$ & $60,206.34$ & $38 \%$ \\
\hline 2000-2006 & $251,224.61$ & $28,492.44$ & $11 \%$ & $13,993.70$ & $6 \%$ & $18,168.63$ & $8 \%$ & $111,191.23$ & $44 \%$ \\
\hline & & & & Exports & & & & & \\
\hline $1973-1979$ & 8,847.11 & 625.59 & $7 \%$ & $2,546.37$ & $29 \%$ & 277.70 & $3 \%$ & 95.44 & $1 \%$ \\
\hline 1980-1989 & 36,309.91 & $1,873.18$ & $5 \%$ & $10,190.84$ & $28 \%$ & $1,148.81$ & $3 \%$ & 7,527.12 & $21 \%$ \\
\hline 1990-1999 & $147,717.00$ & $8,399.88$ & $6 \%$ & $33,480.98$ & $23 \%$ & $4,125.46$ & $3 \%$ & $47,899.64$ & $32 \%$ \\
\hline 2000-2006 & $240,127.13$ & $12,825.06$ & $5 \%$ & $44,501.23$ & $19 \%$ & $5,571.47$ & $2 \%$ & $100,969.60$ & $42 \%$ \\
\hline \multicolumn{9}{|c|}{ Source: Census and Statistics Department, the Government of the Hong Kong Special Administrative Region of the People’s Republic of } & China, “Trade Analysis Section.” \\
\hline \multicolumn{10}{|l|}{ Notes: } \\
\hline \multicolumn{10}{|c|}{ a Average for period, millions of dollars. } \\
\hline b Average for & eriod as a share $\mathrm{o}$ & f total. & & & & & & & \\
\hline
\end{tabular}

Panel A — Import Trade Values with Trading Partners

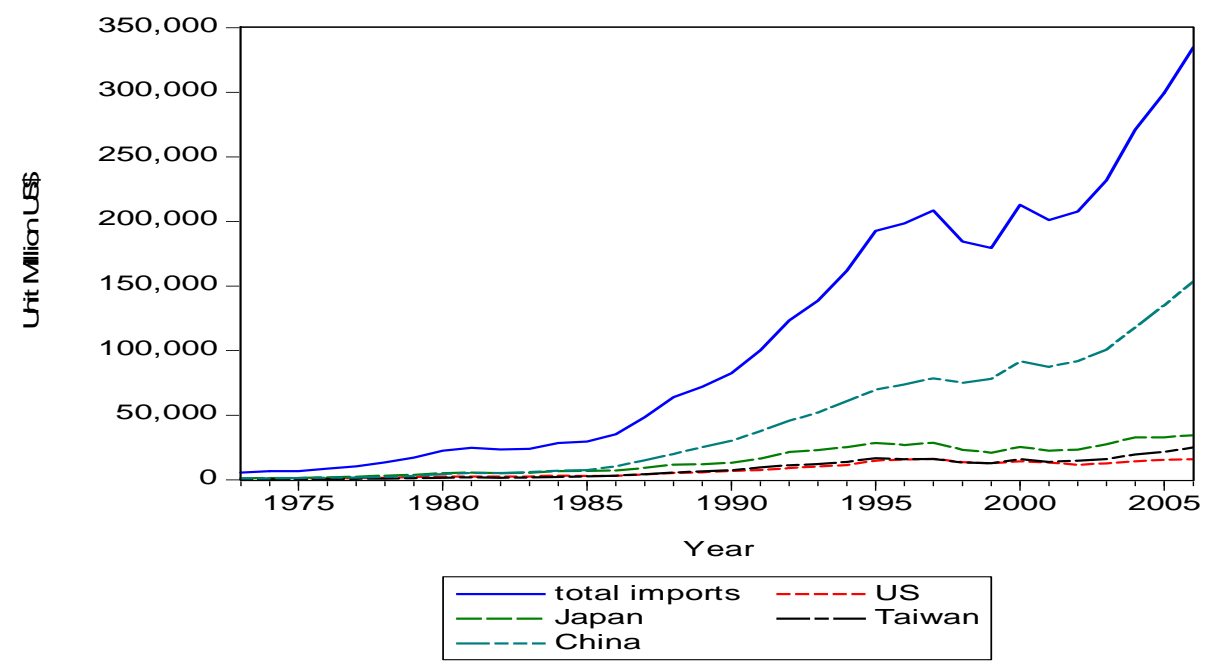

Panel B - Export Trade Values with Trading Partners 


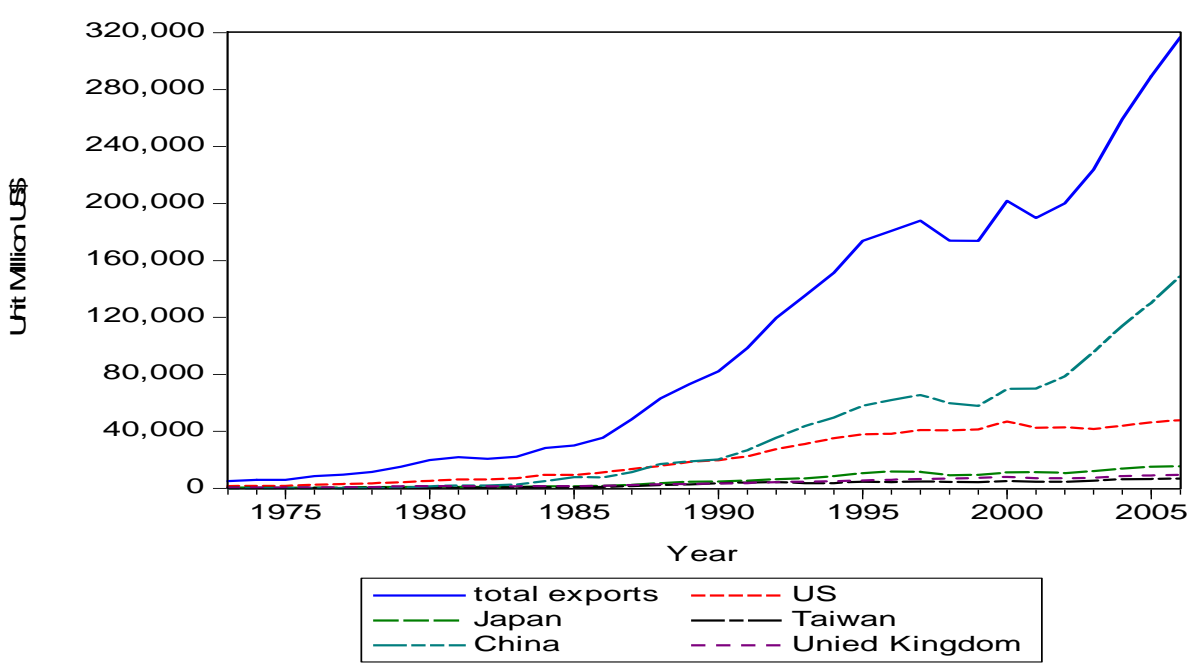

Panel C — Trade with the United States

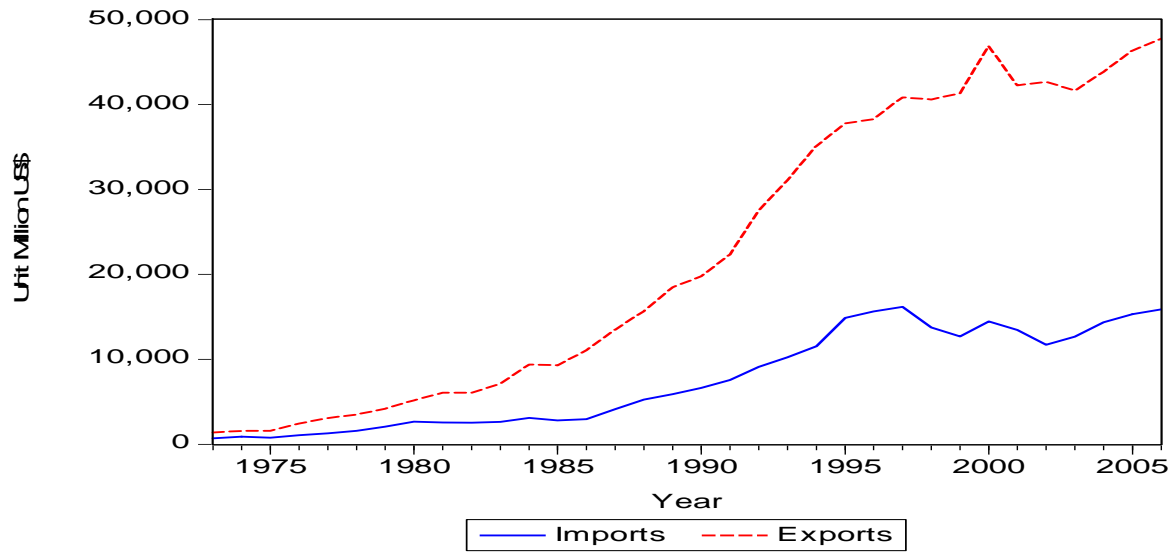

Panel D— Trade with Japan

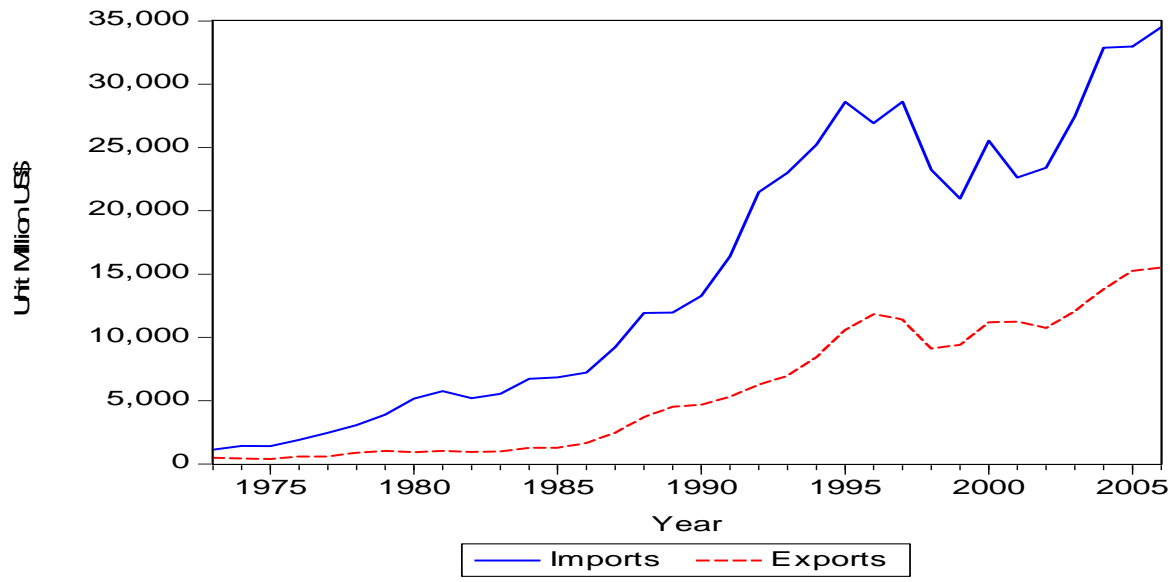


Panel E- Trade with Taiwan

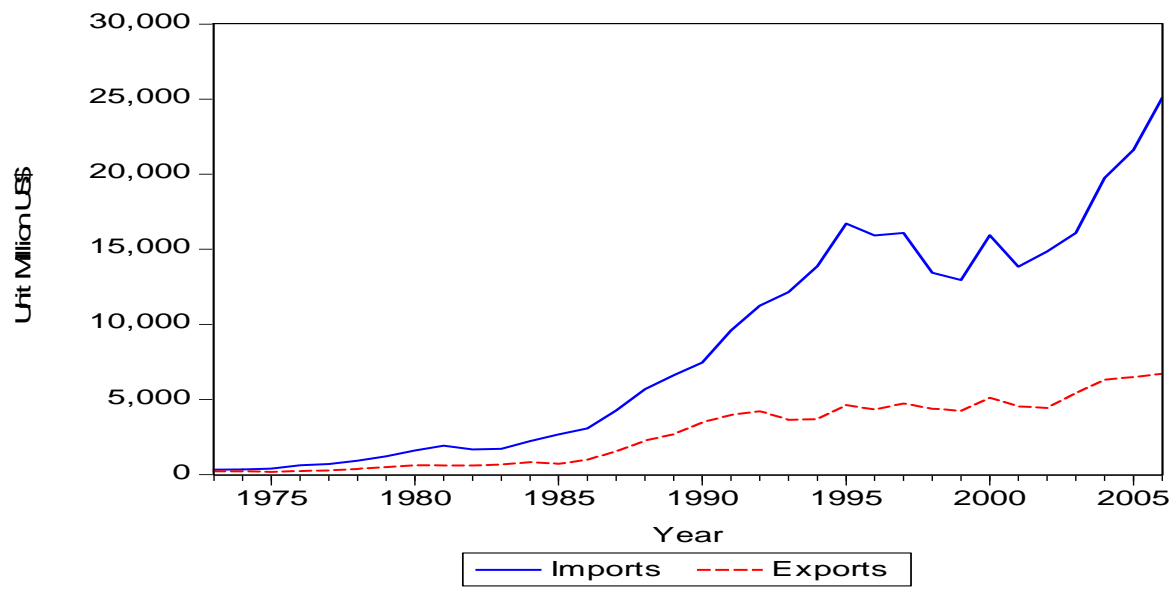

Panel F- Trade with China

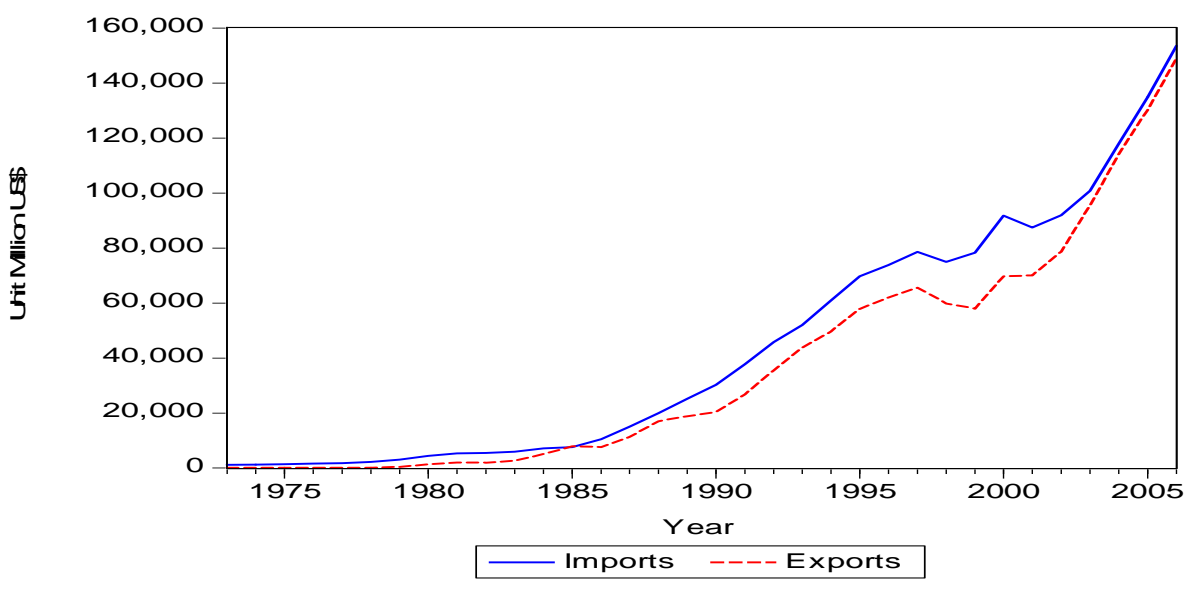

Panel G— Trade with the United Kingdom

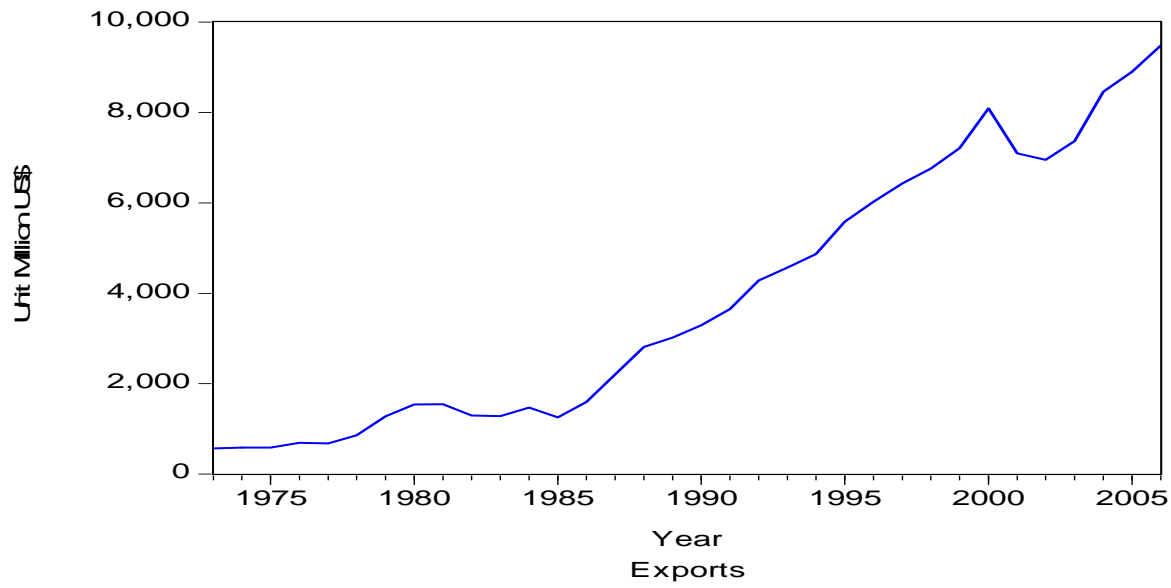

Figure 2. Hong Kong’s Trade with Trading Partners 
According to Table 2 and Figure 2, Hong Kong's exports grew from U.S.\$8.85 billion in 1970s to U.S.\$147.72 billion in 1990s. The largest recipients of Hong Kong's goods were the United Kingdom, the United States, and Japan. However, since 1997, China has replaced the United Kingdom to become the largest trading partner of Hong Kong. During the 2000s, 42\% of Hong Kong's total exports went to China, 19\% to the United States, 5\% to Japan, and 3\% to the United Kingdom, whereas $44 \%$ of its imports came from China, $11 \%$ from Japan, $8 \%$ from Taiwan, and 6\% from the United States.

In this paper we examine how real GDP growth in Hong Kong and Taiwan may be affected by their own past rates as well as those of their trading partners. To that end, we estimate threshold autoregressions for each country. Several studies (Tsay, 1989; Das, 1993; Anderson, 1994; Terasvirta, 1994; Michael, Nobay, and Peel, 1997; Henry and Summers, 2000; and Abdulai, 2002) have found that the nonlinear model estimation may outperform the standard linear model. Various types of nonlinear models have been used to allow for possible asymmetries in various economic relationships. These models include the Markov switching models popularized by Hamilton (1988, 1989), as well as the threshold autoregressive (TAR) model used here, and its smooth transition (STAR) variant.

The remainder of this paper is organized as follows: Section 2 describes the empirical application, Section 3 presents data and discusses results, and Section 4 concludes.

\section{Threshold Regression and Bayesian Approach}

Like the Markov switching model, the TAR model splits the data into two or more regimes that are characterized by different parameter values. In TAR models however, the transitions between these regimes arise endogenously rather than being determined by an exogenous Markov chain. In this paper, we employ Bayesian estimation methods because they provide a straightforward means of assessing the relative support in the data for nonlinear versus linear models. In addition, these methods provide posterior probability distributions for various models, making for tractable model comparisons.(Note 4)

Following Koop and Potter (1998) and Henry and Summers (2000), we estimate a two-regime, first-order threshold autoregressive (TAR) model written as follows:

$$
\text { Model G: } y_{t}=\left(\alpha_{0}+\alpha_{1} x_{t-1}+\varepsilon_{j 1 t}\right) I_{\left(z_{t-d} \leq \gamma\right)}+\left(\beta_{0}+\beta_{1} x_{t-1}+\varepsilon_{j 2 t}\right) I_{\left(z_{t-d}>\gamma\right)}
$$

where $y_{t}=100 \times\left(\ln G D P_{t}^{j}-\ln G D P_{t-1}^{j}\right)$ for $j=H K$ (Hong Kong), $T W$ (Taiwan), $x_{t-1}=100 \times\left(\ln G D P_{t-1}^{i}-\ln G D P_{t-2}^{i}\right)$ for $i=U S$, Japan, Taiwan or Hong Kong and the $\varepsilon_{j}$ terms denote independently and identically distributed white noise processes. The indicator function $I($.$) takes the value of one when the condition in its argument is true, and zero$ otherwise. The threshold variable $z_{t}$ (which is a known function of the data), and the threshold 
value $\gamma$, govern the behavior of $y_{t}$. When $z_{t} \leq \gamma$, the process evolves according to the $\alpha$ coefficients; the $\beta$ coefficients apply in the other regime.

Thus, we consider various models in which $z_{t}$, the threshold variable, is a function of economic growth in the United States, Japan, Taiwan, or Hong Kong. Notice that overseas economic growth (e.g., in the U.S.) can only affect domestic growth indirectly; only lagged values of domestic growth appear on the right-hand side of (0.1). We refer to the model described by (0.1) as model ' $\mathrm{G}$ ', in which the threshold variable is its value $d$ periods ago $\left(z_{t-d}\right)$ to be determined by the data.

In the interest of robustness, we allow for a more agnostic estimation of the timing dimension of the threshold variable by considering two additional specifications:

$$
\begin{aligned}
& \text { Model M: } y_{t}=\left(\alpha_{0}+\alpha_{1} x_{t-1}+\varepsilon_{1 t}\right) I_{\left(z_{t-d}-z_{t-d-1} \leq \gamma\right)}+\left(\beta_{0}+\beta_{1} x_{t-1}+\varepsilon_{2 t}\right) I_{\left(z_{t-d}-z_{t-d-1}>\gamma\right)} \\
& \text { Model A: } y_{t}=\left(\alpha_{0}+\alpha_{1} x_{t-1}+\varepsilon_{1 t}\right) I_{\left(\left(z_{t-1}-z_{t-d}\right) / d \leq \gamma\right)}+\left(\beta_{0}+\beta_{1} x_{t-1}+\varepsilon_{2 t}\right) I_{\left(\left(z_{t-1}-z_{t-d}\right) / n>\gamma\right)}
\end{aligned}
$$

where ' $M$ ', and ' $A$ ' refer to models in which the threshold variable is its $d^{\text {th }}$ lagged difference value $\left(\mathrm{z}_{t-d}-\mathrm{z}_{t-d-1}\right)$; and its average value over the last $d$ periods $\left(z_{t-1}-z_{t-d}\right) / d$, respectively. Again, in all these models, the unknown delay lag, $d$, is determined by the data. We also estimate homoskedastic versions of the three models, denoted as ' $\mathrm{GH}$ ', 'MH', and 'AH.'

If for any of the three specifications (0.1)-(0.3), the threshold variable (contained in $x_{t-1}$ ) is the lagged dependent variable itself, then corresponding equation becomes the self-exciting threshold autoregression (SETAR) model. For example, the SETAR version of model G is:

$$
y_{t}=\left(\alpha_{1} y_{t-1}+\varepsilon_{j 1 t}\right) I_{\left(y_{t-d} \leq \gamma\right)}+\left(\beta_{1} y_{t-1} \varepsilon_{j 2 t}\right) I_{\left(y_{t-d}>\gamma\right)} .
$$

We use Bayes factors to compare the various models. Given a data set D, and two models, $\mathrm{H}$ and $\mathrm{K}$, the Bayes factor (BF) is defined as

$$
B F=\frac{\operatorname{pr}(D \mid H)}{\operatorname{pr}(D \mid K)},
$$

which is the ratio of the marginal probability of the data under model $H$ to its marginal probability under model $K$. The Bayes factor can be rewritten in terms of the prior and posterior odds ratios as follows:

$$
B F=\frac{p r(D \mid H)}{p r(D \mid K)}=\frac{p(H \mid D) / p(H)}{p(K \mid D) / p(K)}
$$

In equation (0.6), the prior odds and posterior odds in favor of model $\mathrm{H}$ are given by 
$\operatorname{pr}(H) / \operatorname{pr}(K)$ and $\operatorname{pr}(H \mid D) / \operatorname{pr}(K \mid D)$ respectively. If all models are considered equally likely a priori, then the Bayes factor is equal to the posterior odds ratio. Higher values of BF (or the posterior odds ratio) indicate more support in the data for model $\mathrm{H}$, and vice versa.( Note 5)

\section{Data and Empirical Results}

We collect data on real gross domestic product (GDP) at constant (2000) market prices in the United States, Japan, and Hong Kong from the St. Louis Fed Economic Data (FRED) and Census and Statistics Department of Hong Kong Special Administrative Region, respectively. Data on Taiwan's GDP at constant (2001) market prices come from National Statistics, Republic of China.(Note 6) The GDP data we extracted is in terms of local currencies of each country in order to investigate the impact of overseas economic activity fluctuations on Taiwan and Hong Kong's economic growth without exchange rate volatility. The data are quarterly and the sample runs from the first quarter of 1973 to the fourth quarter of 2006. ( Note 7)

We estimated (0.2)-(0.3) allowing for up to 12 lags of the dependent variable. The posterior probabilities for all models are presented in Table 3. Note that the sum of G, GH, M, MH, A, and $\mathrm{AH}$ for a given lag length gives the marginal probability of a nonlinear model for that lag length.( Note 8) Thus we derive results shown in Table 3 (and later Table 4) which will serve as our model selection mechanism.

Table 3. Posterior Model Probabilities for Hong Kong

\begin{tabular}{|c|c|c|c|c|c|c|c|}
\hline \multicolumn{8}{|c|}{ Panel A. Threshold in US GDP growth } \\
\hline Lags & G & GH & M & MH & A & $\mathrm{AH}$ & Total \\
\hline 1 & 2.07 & 0.44 & 0.02 & 0.20 & 0.00 & 0.00 & \\
\hline 2 & 0.29 & 0.00 & 0.00 & 0.00 & 0.00 & 0.00 & \\
\hline 3 & 0.00 & 0.01 & 0.00 & 0.02 & 0.00 & 0.03 & \\
\hline 4 & 0.00 & 0.00 & 0.00 & 0.00 & 0.00 & 0.00 & \\
\hline 5 & 0.00 & 0.00 & 0.00 & 0.00 & 0.00 & 0.00 & \\
\hline 6 & 0.00 & 0.00 & 0.00 & 0.00 & 0.00 & 0.00 & \\
\hline 7 & 0.00 & 0.00 & 0.00 & 0.00 & 0.00 & 0.00 & \\
\hline 8 & 0.00 & 0.00 & 0.00 & 0.00 & 0.00 & 0.00 & \\
\hline 9 & 0.00 & 0.00 & 0.00 & 0.00 & 0.00 & 0.00 & \\
\hline 10 & 0.00 & 0.00 & 0.00 & 0.00 & 0.00 & 0.00 & \\
\hline 11 & 0.00 & 0.00 & 0.00 & 0.00 & 0.00 & 0.00 & \\
\hline 12 & 0.00 & 0.00 & 0.00 & 0.00 & 0.00 & 0.00 & \\
\hline Marginal & 2.36 & 0.45 & 0.02 & 0.22 & 0.0 & 0.03 & 3.08 \\
\hline
\end{tabular}




\begin{tabular}{|c|c|c|c|c|c|c|c|c|}
\hline \multicolumn{9}{|c|}{ Panel B. Threshold in Japanese GDP growth } \\
\hline 1 & & 4.28 & 2.16 & 0.05 & 0.16 & 0.00 & 0.00 & \\
\hline 2 & & 0.03 & 0.02 & 0.00 & 0.03 & 0.00 & 0.05 & \\
\hline 3 & & 0.00 & 0.00 & 0.00 & 0.00 & 0.00 & 0.00 & \\
\hline 4 & & 0.00 & 0.00 & 0.00 & 0.00 & 0.00 & 0.00 & \\
\hline 5 & & 0.00 & 0.00 & 0.00 & 0.00 & 0.00 & 0.00 & \\
\hline 6 & & 0.00 & 0.00 & 0.00 & 0.00 & 0.00 & 0.00 & \\
\hline 7 & & 0.00 & 0.00 & 0.00 & 0.00 & 0.00 & 0.00 & \\
\hline 8 & & 0.00 & 0.00 & 0.00 & 0.00 & 0.00 & 0.00 & \\
\hline 9 & & 0.00 & 0.00 & 0.00 & 0.00 & 0.00 & 0.00 & \\
\hline 10 & & 0.00 & 0.00 & 0.00 & 0.00 & 0.00 & 0.00 & \\
\hline 11 & & 0.00 & 0.00 & 0.00 & 0.00 & 0.00 & 0.00 & \\
\hline 12 & & 0.00 & 0.00 & 0.00 & 0.00 & 0.00 & 0.00 & \\
\hline Marginal & & 4.31 & 2.18 & 0.05 & 0.19 & 0.0 & 0.05 & 6.78 \\
\hline \multicolumn{9}{|c|}{ Panel C. Threshold in Taiwanese GDP growth } \\
\hline 1 & & 0.33 & 5.04 & 2.49 & 5.01 & 0.00 & 0.00 & \\
\hline 2 & & 0.00 & 0.01 & 0.00 & 0.04 & 0.01 & 0.08 & \\
\hline 3 & & 0.00 & 0.01 & 0.00 & 0.07 & 0.01 & 0.11 & \\
\hline 4 & & 0.00 & 0.00 & 0.00 & 0.00 & 0.00 & 0.00 & \\
\hline 5 & & 0.00 & 0.00 & 0.00 & 0.00 & 0.00 & 0.00 & \\
\hline 6 & & 0.00 & 0.00 & 0.00 & 0.00 & 0.00 & 0.00 & \\
\hline 7 & & 0.00 & 0.00 & 0.00 & 0.00 & 0.00 & 0.00 & \\
\hline 8 & & 0.00 & 0.00 & 0.00 & 0.00 & 0.00 & 0.00 & \\
\hline 9 & & 0.00 & 0.00 & 0.00 & 0.00 & 0.00 & 0.00 & \\
\hline 10 & & 0.00 & 0.00 & 0.00 & 0.00 & 0.00 & 0.00 & \\
\hline 11 & & 0.00 & 0.00 & 0.00 & 0.00 & 0.00 & 0.00 & \\
\hline 12 & & 0.00 & 0.00 & 0.00 & 0.00 & 0.00 & 0.00 & \\
\hline Marginal & & 0.33 & 5.06 & 2.49 & 5.12 & 0.02 & 0.19 & 13.21 \\
\hline \multicolumn{9}{|c|}{ Panel D. Threshold in Hong Kong GDP growth (SETAR) } \\
\hline Lags & G & $\mathrm{GH}$ & M & $\mathrm{MH}$ & A & $\mathrm{AH}$ & $\mathrm{AR}$ & VAR \\
\hline 1 & 18.37 & 8.95 & 7.71 & 0.21 & 0.00 & 0.00 & 7.70 & 0.33 \\
\hline 2 & 0.01 & 0.05 & 0.45 & 4.04 & 0.03 & 0.01 & 0.34 & 0.00 \\
\hline 3 & 0.00 & 0.00 & 0.00 & 0.00 & 0.27 & 0.00 & 0.29 & 0.00 \\
\hline 4 & 28.12 & 0.00 & 0.00 & 0.00 & 0.00 & 0.00 & 0.02 & 0.00 \\
\hline 5 & 0.00 & 0.00 & 0.00 & 0.00 & 0.00 & 0.00 & 0.00 & 0.00 \\
\hline 6 & 0.00 & 0.00 & 0.00 & 0.00 & 0.00 & 0.00 & 0.00 & 0.00 \\
\hline 7 & 0.00 & 0.00 & 0.00 & 0.00 & 0.00 & 0.00 & 0.00 & 0.00 \\
\hline 8 & 0.00 & 0.00 & 0.00 & 0.00 & 0.00 & 0.00 & 0.00 & 0.00 \\
\hline 9 & 0.00 & 0.00 & 0.00 & 0.00 & 0.00 & 0.00 & 0.00 & 0.00 \\
\hline 10 & 0.00 & 0.00 & 0.00 & 0.00 & 0.00 & 0.00 & 0.00 & 0.00 \\
\hline 11 & 0.00 & 0.00 & 0.00 & 0.00 & 0.00 & 0.00 & 0.00 & 0.00 \\
\hline 12 & 0.00 & 0.00 & 0.00 & 0.00 & 0.00 & 0.00 & 0.00 & 0.00 \\
\hline Marginal & 46.5 & 9 & 8.16 & 4.25 & 0.3 & 0.01 & 8.35 & 0.33 \\
\hline
\end{tabular}


Notes: 'G', 'M' and 'A' refer to models in which the threshold variable is the growth rate; the momentum (i.e., the change in the growth rate); and the average growth rate, respectively, of real GDP growth. 'H' denotes the homoskedastic version of each model. 'AR' is a linear autoregression of the indicated order. 'VAR' refers to the 'Hong Kong equation' from a 4-variable vector autoregression with the growth rates of the US, Japan, Taiwan, and Hong Kong. The rows labeled 'Marginal' give the sum of the probabilities over all lag lengths. The column labeled 'Total' gives the sum of the probabilities for each panel. The sample is from 1973Q1 to 2006 Q4.

The row labeled 'marginal' gives the sum of the probabilities in each column, which indicates the overall support for each of the various model variants. The threshold variable in each model is listed at the top of each panel. Panel D represents the SETAR model and also includes probabilities for two linear specifications; a univariate autoregression (in column 'AR') and the "Hong Kong equation" from a vector autoregression (VAR) model of the four countries' growth rates, (in the 'VAR' column). The VAR model allows for direct linear effects on the Hong Kong economy from each of the other countries.

As is evident from Table 3, there is virtually no support in the data for nonlinear effects on GDP growth in Hong Kong GDP arising from growth rates in the US, Japan, or Taiwan. None of the individual models in panels A-C receives more than about $5 \%$ probability, and only in panel $\mathrm{C}$ does the total probability over all 72 models exceed $10 \%$. The linear specifications in panel D likewise receive very little support from the data, although an AR(1) is more likely than any of the models in the first three panels.

Some form of a SETAR model with no more than four lags seems to be the best fit to the Hong Kong data. The G(4) model has the highest posterior probability at $28.1 \%$, with the one-lag version of that model receiving $18.4 \%$ probability. These two models account for nearly half of the total posterior probability.

Corresponding results for Taiwan GDP growth are shown in Table 4.

Table 4. Posterior Model Probabilities for Taiwan

\begin{tabular}{|c|c|c|c|c|c|c|c|}
\hline \multicolumn{8}{|c|}{ Panel A. Threshold in US GDP growth } \\
\hline Lags & G & GH & M & MH & A & $\mathrm{AH}$ & Total \\
\hline 1 & 0.00 & 0.00 & 0.00 & 0.00 & 0.00 & 0.00 & \\
\hline 2 & 0.01 & 0.01 & 0.01 & 0.03 & 0.03 & 0.05 & \\
\hline 3 & 0.00 & 0.00 & 0.03 & 0.03 & 0.04 & 0.05 & \\
\hline 4 & 0.00 & 0.00 & 0.00 & 0.00 & 0.00 & 0.00 & \\
\hline 5 & 0.00 & 0.00 & 0.00 & 0.00 & 0.00 & 0.00 & \\
\hline 6 & 0.00 & 0.00 & 0.00 & 0.00 & 0.00 & 0.00 & \\
\hline 7 & 0.00 & 0.00 & 0.00 & 0.00 & 0.00 & 0.00 & \\
\hline 8 & 0.00 & 0.00 & 0.00 & 0.00 & 0.00 & 0.00 & \\
\hline 9 & 0.00 & 0.00 & 0.00 & 0.00 & 0.00 & 0.00 & \\
\hline 10 & 0.00 & 0.00 & 0.00 & 0.00 & 0.00 & 0.00 & \\
\hline 11 & 0.00 & 0.00 & 0.00 & 0.00 & 0.00 & 0.00 & \\
\hline 12 & 0.00 & 0.00 & 0.00 & 0.00 & 0.00 & 0.00 & \\
\hline Marginal & 0.01 & 0.01 & 0.04 & 0.06 & 0.07 & 0.1 & 0.29 \\
\hline
\end{tabular}




\begin{tabular}{|c|c|c|c|c|c|c|c|c|c|}
\hline \multicolumn{10}{|c|}{ Panel B. Threshold in Japanese GDP growth } \\
\hline 1 & & 0.00 & & 0.00 & 0.00 & 0.00 & 0.00 & 0.00 & \\
\hline 2 & & 0.17 & & 0.07 & 0.35 & 0.02 & 0.71 & 0.05 & \\
\hline 3 & & 0.00 & & 0.00 & 30.92 & 0.09 & 46.38 & 0.14 & \\
\hline 4 & & 0.04 & & 0.02 & 0.01 & 0.00 & 0.01 & 0.00 & \\
\hline 5 & & 0.00 & & 0.00 & 0.00 & 0.00 & 0.00 & 0.00 & \\
\hline 6 & & 0.00 & & 0.00 & 0.00 & 0.00 & 0.00 & 0.00 & \\
\hline 7 & & 0.00 & & 0.00 & 0.00 & 0.00 & 0.00 & 0.00 & \\
\hline 8 & & 0.00 & & 0.00 & 0.00 & 0.00 & 0.00 & 0.00 & \\
\hline 9 & & 0.00 & & 0.00 & 0.00 & 0.00 & 0.00 & 0.00 & \\
\hline 10 & & 0.00 & & 0.00 & 0.00 & 0.00 & 0.00 & 0.00 & \\
\hline 11 & & 0.00 & & 0.00 & 0.00 & 0.00 & 0.00 & 0.00 & \\
\hline 12 & & 0.00 & & 0.00 & 0.00 & 0.00 & 0.00 & 0.00 & \\
\hline Marginal & & 0.21 & & 0.09 & 31.28 & 0.11 & 47.1 & 0.19 & 78.98 \\
\hline \multicolumn{10}{|c|}{ Panel C. Threshold in Hong Kong GDP growth } \\
\hline 1 & & 0.00 & & 0.02 & 0.01 & 0.00 & 0.00 & 0.00 & \\
\hline 2 & & 0.17 & & 0.03 & 0.36 & 2.08 & 0.73 & 4.17 & \\
\hline 3 & & 0.07 & & 0.24 & 0.38 & 0.59 & 0.57 & 0.88 & \\
\hline 4 & & 0.00 & & 0.00 & 0.02 & 0.00 & 0.03 & 0.00 & \\
\hline 5 & & 0.00 & & 0.00 & 0.00 & 0.00 & 0.00 & 0.00 & \\
\hline 6 & & 0.00 & & 0.00 & 0.00 & 0.00 & 0.00 & 0.00 & \\
\hline 7 & & 0.00 & & 0.00 & 0.00 & 0.00 & 0.00 & 0.00 & \\
\hline 8 & & 0.00 & & 0.00 & 0.00 & 0.00 & 0.00 & 0.00 & \\
\hline 9 & & 0.00 & & 0.00 & 0.00 & 0.00 & 0.00 & 0.00 & \\
\hline 10 & & 0.00 & & 0.00 & 0.00 & 0.00 & 0.00 & 0.00 & \\
\hline 11 & & 0.00 & & 0.00 & 0.00 & 0.00 & 0.00 & 0.00 & \\
\hline 12 & & 0.00 & & 0.00 & 0.00 & 0.00 & 0.00 & 0.00 & \\
\hline Marginal & & 0.24 & & 0.29 & 0.77 & 2.67 & 1.33 & 5.05 & 10.35 \\
\hline \multicolumn{10}{|c|}{ Panel D. Threshold in Taiwan GDP growth (SETAR) } \\
\hline Lags & G & & $\mathrm{GH}$ & $\mathrm{M}$ & $\mathrm{MH}$ & A & $\mathrm{AH}$ & AR & VAR \\
\hline 1 & 0.02 & & 0.00 & 0.12 & 0.04 & 0.00 & 0.00 & 0.00 & 0.00 \\
\hline 2 & 0.18 & & 0.23 & 0.00 & 0.03 & 1.36 & 0.93 & 2.68 & 0.00 \\
\hline 3 & 0.01 & & 0.02 & 0.01 & 0.00 & 0.63 & 0.06 & 3.61 & 0.00 \\
\hline 4 & 0.00 & & 0.00 & 0.00 & 0.00 & 0.00 & 0.00 & 0.25 & 0.00 \\
\hline 5 & 0.00 & & 0.00 & 0.00 & 0.00 & 0.00 & 0.00 & 0.02 & 0.00 \\
\hline 6 & 0.00 & & 0.00 & 0.00 & 0.00 & 0.02 & 0.06 & 0.02 & 0.00 \\
\hline 7 & 0.00 & & 0.00 & 0.00 & 0.00 & 0.00 & 0.00 & 0.02 & 0.00 \\
\hline 8 & 0.00 & & 0.00 & 0.00 & 0.00 & 0.00 & 0.00 & 0.00 & 0.00 \\
\hline 9 & 0.00 & & 0.00 & 0.00 & 0.00 & 0.00 & 0.00 & 0.00 & 0.00 \\
\hline 10 & 0.00 & & 0.00 & 0.00 & 0.00 & 0.00 & 0.00 & 0.00 & 0.00 \\
\hline 11 & 0.00 & & 0.00 & 0.00 & 0.00 & 0.00 & 0.00 & 0.00 & 0.00 \\
\hline 12 & 0.00 & & 0.00 & 0.00 & 0.00 & 0.00 & 0.00 & 0.00 & 0.00 \\
\hline Marginal & 0.21 & & 0.25 & 0.13 & 0.07 & 2.01 & 1.05 & 6.6 & 0.0 \\
\hline
\end{tabular}


Notes: 'G', 'M' and 'A' refer to models in which the threshold variable is the growth rate; the momentum (i.e., the change in the growth rate); and the average growth rate, respectively, of real GDP growth. 'H' denotes the homoskedastic version of each model. 'AR' is a linear autoregression of the indicated order. 'VAR' refers to the 'Hong Kong equation' from a 4-variable vector autoregression with the growth rates of the US, Japan, Taiwan, and Hong Kong. The rows labeled 'Marginal' give the sum of the probabilities over all lag lengths. The column labeled 'Total' gives the sum of the probabilities for each panel. The sample is from 1973Q1 to 2006 Q4.

In contrast to the results for Hong Kong, panel B of this table shows considerable support for a nonlinear specification with an external threshold in Japan. Nearly $80 \%$ of the total probability is allocated to models in this panel, with the majority going to the $A(3)$ and $M(3)$ models. Linear models receive roughly the same (lack of) support as in Table 3. There is also little or no evidence for nonlinear effects arising from past growth in the U.S. or Hong Kong.

We draw from the results of Table 3 and Table 4 to select an appropriate specification for Hong Kong and Taiwan. Thus, we estimate the highest-probability model, as suggested by tables 3 and 4, for each country in order to gain further insight into the different types of nonlinear effects that seem to be in evidence.(Note 9)

Table 5 shows the parameter estimates for the G(4) SETAR model for Hong Kong.

Table 5. Parameter Estimates, G(4) SETAR model for Hong Kong

\begin{tabular}{ccccc}
\hline Parameter & Posterior Mean & Posterior SD & \multicolumn{1}{c}{ MLE } & Asymptotic SE \\
\hline$\alpha_{0}$ & 0.6706 & 0.1905 & 0.0890 & 0.6263 \\
$\alpha_{1}$ & 0.2899 & 0.0758 & -0.0599 & 0.1969 \\
$\alpha_{2}$ & 0.1329 & 0.0614 & -0.0555 & 0.1695 \\
$\alpha_{3}$ & 0.2196 & 0.0580 & 0.4977 & 0.1554 \\
$\alpha_{4}$ & -0.2035 & 0.0954 & -0.0049 & 0.1561 \\
$\sigma_{1}{ }^{2}$ & 1.1980 & 0.1408 & 4.3410 & -- \\
$\beta_{0}$ & 1.5810 & 0.9103 & 1.3870 & 0.3636 \\
$\beta_{1}$ & -0.0687 & 0.1789 & 0.0863 & 0.1269 \\
$\beta_{2}$ & -0.2733 & 0.1837 & 0.0640 & 0.0872 \\
$\beta_{3}$ & 0.1609 & 0.2061 & 0.0796 & 0.1403 \\
$\beta_{4}$ & 0.0465 & 0.2305 & -0.0688 & 0.0943 \\
$\sigma_{2}^{2}$ & 6.1600 & 0.8792 & 2.5330 & -- \\
$\gamma$ & 1.6990 & -- & -0.2054 & -- \\
\hline
\end{tabular}

Here, the threshold variable is the growth rate of Hong Kong GDP four quarters ago. (Note 10) Results suggest that when growth a year ago was below about $1.7 \%$ per quarter, Hong Kong GDP growth averages about 1.2\% per quarter, with a standard deviation of $1.1 \%$ per quarter.(Note 11) All four lags are significant in this regime. On the other hand, when the growth rate was above the threshold a year ago, none of the AR lags are significant. The average growth rate in this regime is about $1.6 \%$ per quarter, with a standard deviation of $2.5 \%$. 
In Table 6, we show the A(3) model for Taiwan with a threshold effect in Japan. Specifically, the threshold variable now is the average growth rate in Japan over the previous three quarters. (Note 12)

Table 6. Parameter Estimates, A(3) Model for Taiwan, Threshold in Japanese GDP Growth

\begin{tabular}{ccccc}
\hline Parameter & Posterior Mean & Posterior SD & \multicolumn{1}{l}{ MLE } & Asymptotic SE \\
\hline$\alpha_{0}$ & 0.3523 & 0.6784 & 0.4299 & 0.3434 \\
$\alpha_{1}$ & 0.8874 & 0.5063 & 0.5531 & 0.1771 \\
$\alpha_{2}$ & 0.5525 & 0.3754 & 0.3449 & 0.1405 \\
$\alpha_{3}$ & -0.3735 & 0.4673 & -0.0157 & 0.1758 \\
$\sigma_{1}{ }^{2}$ & 3.4200 & 0.7468 & 1.8810 & -- \\
$\beta_{0}$ & 0.6123 & 0.2153 & 0.9995 & 0.2941 \\
$\beta_{1}$ & 0.2069 & 0.0768 & 0.0666 & 0.1074 \\
$\beta_{2}$ & 0.2415 & 0.0757 & 0.1782 & 0.1066 \\
$\beta_{3}$ & 0.2469 & 0.0734 & 0.3479 & 0.0889 \\
$\sigma_{2}{ }^{2}$ & 1.0250 & 0.1030 & 1.1110 & -- \\
$\gamma$ & -0.2376 & -- & -0.1998 & -- \\
\hline
\end{tabular}

Notes: The maximum likelihood estimates of the regime-specific variances are obtained by averaging the squared errors in each regime; no standard error is available for this procedure. Similarly, the MLE of $\gamma$ is obtained via sequential OLS, which also yields no standard error.

The parameter estimates suggest that relatively slow growth in Japan (less than $-0.24 \%$ per quarter over the past three quarters) is bad news for Taiwan. Growth in this regime averages about $0.35 \%$ per quarter, with a standard deviation of about $1.8 \%$. None of the AR lags are significant in this regime.(Note 13) Strong growth in Japan over the past three quarters results in average growth in Taiwan of about $2 \%$ per quarter, with a standard deviation of $1.01 \%$. All of the AR coefficients are significant in this regime, and imply a stationary, mean-reverting process for GDP growth.

Taken together, the results of these models suggest that GDP growth in Japan may have significant spillover effects on the Taiwanese economy.

\section{Conclusion}

This paper employs a threshold autoregression model (TAR) estimated with Bayesian methods to examine how real GDP growth in Taiwan and Hong Kong is affected by domestic and overseas economic activity. Economic activity in both countries seems to be well-described by threshold models, but of significantly different kinds. GDP growth in Hong Kong's major trading partners does not seem to affect its own growth rate- either linearly or nonlinearly. A linear VAR receives little support in the data, whereas models with thresholds determined by GDP growth in the U.S., Japan or Taiwan account for, at most, a small fraction of the posterior probability. The nonlinearity for Hong Kong GDP growth seems to be of the SETAR type, with a delay of one year.

In contrast, there seems to be a significant spillover effect from the Japanese economy to that 
of Taiwan. Two models with thresholds determined by Japanese GDP growth receive over $75 \%$ posterior probability. As long as Japanese economic growth is faster than about $-0.24 \%$ per quarter, Taiwan's growth averages about $2 \%$ per quarter.

\section{References}

Abdulai, A. (2002). Using threshold cointegration to estimate asymmetric price transmission in the Swiss Pork Market. Applied Economics, 34, 69-87. http://dx.doi.org/10.1080/00036840110054035

Anderson, H. M. (1997). Transaction costs and nonlinear adjustment toward equilibrium in the US treasure bill market. Oxford Bulletin of Economics and Statistics, 59(4), 465-84. http://dx.doi.org/10.1111/1468-0084.00078

Baldwin, R.E. (2004). Openness and Growth: What's the Empirical Relationship. In Challenges to Globalization. Baldwin and Winters eds, in NBER Volume ISBN: 0-262-03615-4. http://dx.doi.org/10.7208/chicago/9780226036557.003.0014

Borensztein, E., De Gregorio, J., \& Lee, J.W. (1998). How does foreign direct investment affect economic growth? Journal of International Economics, 45(1), 115-135. http://dx.doi.org/10.1016/S0022-1996(97)00033-0

Das, S. R. (1993). Mean rate shifts and alternative models of the interest rate: theory and evidence. Working Paper, Stern School of Business.

Dollar, D., \& Kraay, A. (2003). Institutions, Trade, and Growth. Journal of Monetary Economics, 50(1), 133-162. http://dx.doi.org/10.1016/S0304-3932(02)00206-4

Frankle, J.A., \& Romer, D. (1999). Does Trade Cause Growth? The American Economic Review, 89(3), 379-399. http://dx.doi.org/10.1257/aer.89.3.379

Geweke, J., \& Terui, N. (1993). Bayesian threshold autoregressive models for nonlinear time series. Journal of Time Series Analysis, 14, 441-54. http://dx.doi.org/10.1111/j.1467-9892.1993.tb00156.x

Hamilton, J. D. (1988). Rational expectations econometric analysis of changes in regime: an investigation of the term structure of interest rates. Journal of Economic Dynamics and Control, 12, 285-423. http://dx.doi.org/10.1016/0165-1889(88)90047-4

Hamilton, J. D. (1989). A new approach to the economic analysis of nonstationary time series and the business cycle. Econometrica, 57(2), 357-84. http://dx.doi.org/10.2307/1912559

Henry, O. T., \& Summers, P. (2000). Australian economic growth: nonlinearities and international influences. The Economic Record, 76(235), 365-373. http://dx.doi.org/10.1111/j.1475-4932.2000.tb00033.x

Keller, W. (2004). International Technology Diffusion. Journal of Economic Literature, 42, 752-782. http://dx.doi.org/10.1257/0022051042177685 
Koop, G. (2003). Bayesian Econometrics. J. Wiley.

Koop, G., \& Potter, S. M. (1998). Bayes factors and nonlinearity: evidence from economic time series. Journal of Econometrics, 88, 251-281. http://dx.doi.org/10.1016/S0304-4076(98)00031-1

Koop, G., Pesaran, M. H., \& Potter, S. M. (1996). Impulse response analysis in nonlinear multivariate models. Journal of Econometrics, 74, 119-147. http://dx.doi.org/10.1016/0304-4076(95)01753-4

Levine, Ross \& Renelt, David. (1992). A Sensitivity Analysis of Cross-Country Growth Regressions. American Economic Review, 82(4), 942-63.

Michael, P., Nobay, R. A., \& Peel, D. A. P. (1997). Transactions costs and nonlinear adjustment in real exchange rates: an empirical investigation. The Journal of Political Economy, 105(4), 862-879. http://dx.doi.org/10.1086/262096

Rodriguez, F., \& Rodrik, D. (2001). Trade Policy and Economic Growth: A Skeptic's Guide to the Cross-National Evidence. In Challenges to Globalization. Bernanke and Rogoff eds, in NBER Macroeconomics Annual Vol. ISBN: 0-262-02503-5.

Sachs, J., \& Warner, A. (1995). Economic Reform and the Progress of Global Integration. Brookings Paper on Economic Activity, 1, 1-18. http://dx.doi.org/10.2307/2534573

Terasvirta, T. (1994). Specification, estimation, and evaluation of smooth transition autoregressive models. Journal of the American Statistical Association, 425(89), 208-218.

Trefler, D. (2004). The Long and the Short of the Canada-U.S. Free Trade Agreement. American Economic Review, 94, 870-895. http://dx.doi.org/10.1257/0002828042002633

Tsay, R. S. (1989). Testing and modeling threshold autoregressive processes. Journal of the American Statistical Association, 84(405), 231-40. http://dx.doi.org/10.1080/01621459.1989.10478760

\section{Notes}

Note 1. See Frankle and Romer (1999) "gravity model".

Note 2. See Sachs and Warner (1995) and Keller (2004) for two such studies.

Note 3. Trade shares are from the Nations' Encyclopedia, available online at http://www.nationsencyclopedia.com/economies/Asia-and-the-Pacific/, under TaiwanINTERNATIONAL-TRADE and Hong-Kong-INTERNATIONAL-TRADE, respectively.

Note 4. See Geweke and Terui, (1993) and Koop and Potter (1999), for more discussion of the advantages of Bayesian methods in this class of models.

Note 5. Koop and Potter (1998) and Henry and Summers (2000) show how Bayes factors can 
be used to select a leading model from among several alternatives.

Note 6. For consistency, the data were adjusted to be at constant (2000) in this study.

Note 7. The starting date is the earliest point at which Hong Kong's real GDP data are available. Hong Kong and Taiwanese GDP data were seasonally adjusted using the X-12 procedure implemented in gretl.

Note 8. As computed by the Bayes Factor.

Note 9. As an alternative, it would have been possible to compute parameter estimates that are averaged across all of the 312 different models for each country but we feel estimating the models that the BF selects is the better way to go.

Note 10. The estimates in Table 5 are actually weighted averages over all possible values of $d$ from 1 to 4 , with weights equal to the posterior model probability. However, the model with $d=4$ receives at least $99.99 \%$ probability.

Note 11. The regime-specific average growth rates are computed as $\mu_{1}=\alpha_{0}\left(1-\sum_{i=1}^{p} \alpha_{i}\right)^{-1}$ and $\mu_{2}=\beta_{0}\left(1-\sum_{i=1}^{p} \beta_{i}\right)^{-1}$, respectively.

Note 12. As in Table 5, these estimates are weighted averages of models with $d=2$ or 3 . The posterior probability for the latter model is $99.6 \%$.

Note 13. Note that the Bayesian point estimates imply that this regime is non-stationary, as the sum of the AR coefficients exceeds one. The average of $0.35 \%$ per quarter assumes that these coefficients are in fact zero.

\section{Copyright Disclaimer}

Copyright reserved by the author(s).

This article is an open-access article distributed under the terms and conditions of the Creative Commons Attribution license (http://creativecommons.org/licenses/by/3.0/). 